\title{
The Debt and Mental Health Evidence Form
}

\section{A tool for health professionals and lenders dealing with customers with self-reported mental health problems}

\author{
Chris Fitch, Robert Chaplin, ${ }^{1}$ Simon Tulloch²
}

The Psychiatrist (2010), 34, 95-100, doi: 10.1192/pb.bp.109.025023

'The Royal College of Psychiatrists' Research Unit, London; ${ }^{2}$ Newham Centre for Mental Health, East London NHS Foundation Trust

Correspondence to Chris Fitch (cfitch@rcpsych.ac.uk)

\begin{abstract}
Aims and method To develop a standardised clinical information form which helps health professionals provide clear and relevant information about individuals who believe mental disorders affect their ability to repay debt and have consented to creditor organisations or money advisors approaching professionals for evidence. The six-question form was evaluated by three stakeholder groups.
\end{abstract}

\begin{abstract}
Results Overall, 35 responses were received from creditors/money advisors, 28 from mental health professionals and 29 from service users/carers. All questions scored acceptable levels of clarity and three questions scored acceptable relevance levels. Qualitative data were used to revise questions on the basis of concerns expressed by stakeholders about sharing diagnostic data, providing prognoses, and the risk of creditor misunderstanding.
\end{abstract}

Clinical implications The form is likely to be an acceptable standardised means by which health professionals can elicit information on debt from individuals with mental health problems, for use by creditor organisations or money advisors. The results of a pilot study are awaited.

Declaration of interest C.F. and R.C. provided guidance as members of the 2006/7 Money Advice Liaison Group national working party on debt and mental health.
British adults with mental disorders are three times more likely to report being in debt than those without mental disorders. ${ }^{1}$ Policy initiatives such as the UK government strategy Tackling Over-Indebtedness ${ }^{2}$ and Mind's 'In the Red' campaign ${ }^{3}$ have identified mental ill health as both a consequence and determinant of debt. Meanwhile, in the financial services sector, voluntary guidelines have recently been published on managing and collecting debts from people with mental health problems. ${ }^{4}$

However, it is contended that when taking debt recovery action, organisations owed money still do not adequately consider information provided about customers' mental health. ${ }^{3}$ This may result in inappropriate, mentally distressing, and sometimes illegal action being taken during debt recovery. ${ }^{3,5}$ Furthermore, where customers consent to creditors requesting information from health professionals, difficulties have been reported: ${ }^{4,6}$

- variability in the type and amount of evidence requested

- ambiguous instructions or unrealistic expectations concerning what information health professionals should provide

- delays, refusals or payment requests from health professionals approached to provide evidence
- poor-quality and irrelevant information provided

- often heightened customer distress at an already difficult time.

Recent UK guidelines ${ }^{4}$ for creditors (including banks and debt collection agencies) and money advisors on working with indebted customers with mental health problems have therefore called for a standardised approach which overcomes these difficulties, and which also meets legal requirements for communicating and processing sensitive personal data detailed in the UK Data Protection Act 1988.

This paper reports findings from the evaluation of one potential tool: the Debt and Mental Health Evidence Form (DMHEF). The DMHEF aims to standardise the existing situation where creditors encounter individuals experiencing debt problems who self-report a mental health condition is affecting their ability to repay. In such situations, creditors (with customer consent) may request written evidence from a mental health professional who knows the customer. Alternatively, money advisors can request evidence on the individual's behalf to negotiate with creditors. Critically, the DMHEF attempts to minimise the time and resources that providing such information may take a health professional, while improving the likelihood of effective creditor decisionmaking. Representing the first stage of a larger development 
programme, this paper presents quantitative and qualitative results on the evaluation of question content and format of the DMHEF by three stakeholder groups: creditors and money advisors, mental health professionals, and those directly affected by debt and mental health - service users and carers. The second stage - a process evaluation of DMHEF use in real-life creditor, advice and health settings is currently being organised.

\section{Method}

\section{Generating questions}

The Money Advice Liaison Group (MALG) - a forum which brings together creditors, money advisors, government and other organisations - commissioned the research leading to the development of the DMHEF, with funding provided by the Money Advice Trust's research grant programme. The programme ran from March 2007 to June 2008. Draft questions were developed through facilitated discussion sessions with MALG's working party on debt and mental health. These included creditors, money advice agencies, mental health professional bodies, and service user organisations. Identified issues were summarised in six draft questions (Table 1).

\section{Study sample and measurement}

The draft DMHEF was evaluated via a postal survey of a purposive sample of mental health professionals, representatives from the creditor/money advice sectors, and service users and carers. Respondents rated each question for clarity - whether it was clear what information health professionals should provide (on a scale of yes/no/don't know) and relevance - helping creditors understand whether/how mental disorders affect individuals' money management (on a scale of $3=$ highly relevant, $2=$ quite relevant, 1 =somewhat relevant, and $0=$ not relevant). Respondents also provided qualitative comments on each question. The study received the National Health Service research and ethics approval.

Mental health professionals were recruited from community mental health teams (CMHTs) in a mental health trust where consultant psychiatrists and CMHT managers distributed study packs to CMHT staff to return by post anonymously. Participation in the study was open to medical and non-medical CMHT staff who provided treatment or support to patients (administrative staff were excluded). This reflected published guidance for creditor and money advisors to treat evidence provided by a range of medical and non-medical professionals equally, rather than only valuing information provided by 'the doctor'.

Staff also did not need previous experience of working with clients with debt and mental health problems, for two reasons. First, in 'real-life' situations, any CMHT staff member who provided treatment or support to patients could receive a request to complete the DMHEF, and not just those with prior experience of patient debt. The DMHEF has been designed to allow non-medical staff to complete it, although some staff may wish to consult with medical colleagues regarding particular patient information.

Table 1 Form development: from draft to final Debt and Mental Health Evidence Form (total number of participants $N=92)$

First draft of the form, original order

Revised form, final order (original/draft question number)

\begin{tabular}{|c|c|c|c|}
\hline Question & $\begin{array}{l}\text { Clarity, \% } \\
\text { yes }(n)\end{array}$ & $\begin{array}{l}\text { Relevance, } \\
\text { \% highly } \\
\text { relevant } \\
(n)\end{array}$ & Revised questions \\
\hline $\begin{array}{l}\text { 1. What is the name of the mental health problem } \\
(M H P) \text { ? }\end{array}$ & $81.4(86)$ & $52.2(90)$ & $\begin{array}{l}\text { 1. What is the name of the mental health problem (MHP)? } \\
\text { (1) }\end{array}$ \\
\hline $\begin{array}{l}\text { 2. Is the patient receiving treatment or support } \\
\text { for the MHP? (yes/no/don't know) }\end{array}$ & $83.8(80)$ & 46.1 (89) & $\begin{array}{l}\text { 2. If applicable, how does the patient's MHP currently } \\
\text { affect their ability to deal with money? (5) }\end{array}$ \\
\hline $\begin{array}{l}\text { 3. Is the MHP temporary, permanent or } \\
\text { intermittent? }\end{array}$ & $75.3(77)$ & 51.8 (85) & $\begin{array}{l}\text { 3. Can you describe any other relevant impact/effect that } \\
\text { the patient may experience in their everyday life due to } \\
\text { their MHP? (4) }\end{array}$ \\
\hline $\begin{array}{l}\text { 4. Can you explain the general impact the MHP } \\
\text { currently has on the everyday life of the patient/ } \\
\text { client? }\end{array}$ & $92.4(79)$ & 73.0 (89) & $\begin{array}{l}\text { 4. If the patient is receiving treatment or support for their } \\
\text { MHP, is there any aspect of this which affects their ability } \\
\text { to manage money? (2) }\end{array}$ \\
\hline $\begin{array}{l}\text { 5. Does the MHP currently affect their ability to } \\
\text { deal with money? }\end{array}$ & $89.0(82)$ & 85.4 (89) & $\begin{array}{l}\text { 5a. If relevant, can you indicate how your patient's MHP } \\
\text { may result in the individual experiencing difficulties in being } \\
\text { contacted by telephone, letter or in person? } \\
5 \text { b. If relevant, please indicate the best way of } \\
\text { communicating with/contacting your patient. (6) }\end{array}$ \\
\hline $\begin{array}{l}\text { 6. The recovery of debts from the patient may } \\
\text { result in contact being made by a lender, debt } \\
\text { collection agencies or debt buyers. This contact } \\
\text { could be by telephone, letter or in person. Is there } \\
\text { any information you can provide about your } \\
\text { patient's/client's ability to deal with such } \\
\text { communication? }\end{array}$ & $83.3(78)$ & $70.0(80)$ & $\begin{array}{l}\text { 6a. When was the date of first onset of the MHP or } \\
\text { provision of first treatment for this? } \\
6 \mathrm{~b} \text {. When was the date of onset of the most recent } \\
\text { episode? } \\
6 \mathrm{c} \text {. Is the episode currently ongoing? (3) }\end{array}$ \\
\hline Global assessment of the form & $88.9(72)$ & 70.7 (75) & \\
\hline
\end{tabular}


Second, it was not clear whether it would be feasible to recruit a sample which would only comprise staff with experience of patient debt in the time available. Professionals from creditor/money advice organisations were included due to their decision to attend a MALG workshop on debt and mental health at a UK conference on money advice. Service users and carers were recruited through an advert distributed via Rethink's and Mind's respective networks of users and carers. The advert invited individuals with a previous or current experience of being in debt, or providing care for someone who was or had been in debt, to contact the research team. No measure was taken of the degree of indebtedness or functional impairment. These methods of questionnaire distribution did not allow for the calculation of an overall response rate and could be more likely to include participants with an interest in the issue.

\section{Analysis}

Quantitative data were analysed using SPSS version 16 for Windows. Qualitative data were analysed using a thematic content approach. A coding frame for the data-set was developed, question responses were independently coded by C.F. and R.C., and a final coded data-set was agreed at a consensus meeting. Thematic counts and deviant case analysis informed the revision of the wording of the questions.

\section{Modification to the form}

Findings from the questionnaire were used to revise the DMHEF. Quantitative analysis identified statistically significant group score differences (non-parametric $\chi^{2}$ or Fisher's test and ANOVA) and those questions where less than $70 \%$ of participants positively rated their clarity or relevance ('yes' or 'highly relevant'). Questions which did not meet this acceptability threshold were revised. These revisions drew on the qualitative analysis of participants' comments about that question.

\section{Results}

\section{Participant numbers}

Overall, we received 92 responses. The evaluation was completed by 28 mental health professionals (10 psychiatrists, 6 community psychiatric nurses, 4 social workers, 3 support workers, 1 occupational therapist, and 4 unknown), 21 service users and 8 carers. For the above two groups (service users and carers were counted as one group) a response rate cannot be calculated because of the recruitment method (as discussed earlier). Also, 35 creditor/money advice professionals completed the evaluation, including 17 from the money advice sector (e.g. Citizens Advice Bureau) and 18 from credit organisations.

\section{Quantitative data}

Table 1 presents clarity and relevance ratings of the draft DMHEF questions. Rating differences between groups were not statistically significant; aggregate group data are therefore presented.

\section{Clarity of questions}

Ratings of question clarity were evaluated by asking respondents: 'Does this question make it clear what information is needed to answer it?' (yes/no/don't know). Table 1 presents data on the percentage of respondents answering 'yes' to each question: at least three-quarters reported that all six questions were clear. The highest rated question was question 4: 'Can you explain the general impact this mental health problem currently has on the everyday life of the patient/client?', with $92.4 \%$ rating it as clear. The lowest rated was question 3: 'Is the mental health problem temporary, permanent or intermittent?', with $75.3 \%$ rating it as clear.

\section{Relevance of questions}

Ratings of question relevance were established through asking respondents: 'In terms of the aims of the form, how relevant is the question?' (answer options were between $0=$ not relevant to $3=$ highly relevant). Although all six questions received modal ratings of 'highly relevant', only question 4 (impact of condition on everyday life), question 5 (impact of condition on money management), and question 6 (issues about debt recovery) were rated by $\geqslant 70 \%$ of respondents as 'highly relevant'.

\section{Qualitative results}

For those questions rated by less than $70 \%$ of respondents as 'highly relevant', we conducted a thematic analysis of respondents' qualitative comments to identify any potential problems with the questions. The respective issues that emerged were those concerning diagnosis (question 1), treatment (question 2), and prognosis (question 3). Additionally, across all three questions, concern about the potential of creditors misunderstanding clinical information was repeatedly voiced.

\section{Diagnosis}

Question 1 of the DMHEF asks health professionals (with patient consent) to provide diagnostic information. Of 53 respondents who provided comments, 15 perceived this question as discriminatory, breaching confidentiality, or irrelevant. This included eight service users/carers, four health professionals, and three creditor/money advice professionals. Comments included:

Service user: Naming health problems is unnecessary. Breach of confidence and may stigmatise certain people with certain problems as bank people may have preconceived ideas. They don't need to know the name of the condition - just how it affects money stuff.

Psychiatrist: [There is a] problem of confidentiality [and] giving outside agencies a diagnosis.

In contrast, 12 respondents identified diagnostic information as relevant. These were predominately from creditors/money advisors $(n=7)$, with four health/social care professionals and one carer. Creditor/money advice respondents thought the question was 'straightforward and necessary' and 'very relevant as long as non-medical jargon is used'. Mental health professionals commented on the need to retain the term 'diagnosis' in the question wording, 
whereas one carer suggested that a list of common mental health diagnoses should be used to assist completion.

\section{Treatment}

Question 2 of the DMHEF asks whether individuals are receiving treatment or support for mental health problems (yes/no/don't know). In total, 50 respondents commented, with 30 requesting a follow-up question to allow this treatment or support to be specified:

Advisor: What is treatment or support? Should this be more clearly defined or should there be a follow-up question? E.g. is the client on medication? Does the client have a [community psychiatric nurse]/support worker, etc? What kind of treatment?

From this subgroup, 20 creditors/money advisors requested more detailed information, including whether treatment had implications for individuals' financial situation:

Advisor: May need more information in terms of what treatment is received, i.e. if regular attendance to mental health specialist required, creditors may need to know this in relation to expenses. Plus prescription costs.

Creditor: Creditors need to know frequency and type of treatment and what the implications are, e.g. cannot work, can still work.

Other creditor/money advice professionals asked for data on periods of psychiatric hospital stay, including providing data on use of the Mental Health Act. In contrast, 7 health professionals and 16 service users and carers reported problems with the question, raising similar concerns to those in question 1 about confidential and non-relevant information being shared.

\section{Prognosis}

In total, 44 respondents commented on question 3 which asks about the nature (duration) of an individual's mental health problem: 17 of the 22 creditors/advisors who answered wanted health professionals to provide an indication of how long the period of mental ill health was likely to last for:

Advisor: Make it plain how long each episode lasts. E.g. is it years or a couple of weeks?

However, three health professionals indicated it would be 'difficult to give a time scale' and this 'may not... address directly the level of difficulty experienced by people [and] could create a false impression of... difficulty over a long time period'. Five service users and carers reported that any prognosis may give creditors an 'unrealistic idea [the] situation will improve'.

\section{Creditor misunderstanding}

The most frequently reported issue across all six of the DMHEF questions focused on the capacity of creditors to interpret mental health information. Respondents voiced a concern that although the DMHEF might provide creditors with improved information, this would not necessarily translate into better decision-making:
Service user: I suspect that many of the recipients (creditors) will have a limited and in some cases flawed understanding of some mental health issues. The question may be very useful but great care needs to be taken.

However, ten creditors/advisors also recognised the potential for misunderstanding as an issue (compared with eight health professionals and ten service users and carers):

Creditor: A concern must be the ability of the recipient of this form to interpret the information given in it. Unfortunately this doesn't lie within the form itself.

This recognition was further reflected in the eight creditors/ advisors calling for education and training to address deficiencies in their mental health knowledge.

\section{Other themes}

Some respondents were concerned about the potential negative impact on individuals' mental health following written, telephone or personal contact by creditors (five responses). Others stated that if contact was made by creditors, a specific third party or advocate (e.g., a mental health worker, relative or money advisor) should deal with this on behalf of the client (six responses). Finally, comments about the overall form yielded concerns about confidentiality and ownership of information and authority for its release. However, none specifically referred to the Data Protection Act.

\section{Discussion}

\section{Main findings}

The quantitative stage of the study demonstrated that all groups of stakeholders rated the six DMHEF questions with high levels of clarity and relevance, with no statistically significant differences between stakeholder groups. Aggregate respondent data indicated that more than $70 \%$ of respondents rated all questions as clearly stating what information was needed to answer them. In contrast, three questions were rated by more than $70 \%$ of respondents as being highly relevant to the aim of helping creditors understand whether and how mental disorders affect individuals' money management.

Qualitative analysis was used to identify potential reasons why these three DMHEF questions scored less than $70 \%$ relevance. This analysis indicated that participants perceived the sharing of diagnostic information between health and creditor sectors (question 1) as a contentious issue. Furthermore, requests (mainly from creditor/money advice respondents) for health professionals to provide more detailed information about current and previous treatment (question 2), and also a prognosis (question 3), were worrying to many participants. This was compounded by the repeated concern - voiced across all participant groups - about creditors'/money advisors' capacity to interpret information about peoples' mental health problems. 


\section{Modifications to the DMHEF}

Modifying the DMHEF subsequently meant striking a balance between providing the minimum of relevant personal information about individuals to better inform creditors'/advisors' action (and potentially benefit individuals' health and financial circumstances), while protecting the majority of personal information from being unnecessarily shared across the health and commercial sectors. This entailed three main revisions.

First, introducing a 'screening' question which established whether a health professional need complete a full DMHEF for the individual concerned. This aimed to avoid any unnecessary release of further clinical information to creditors/money advisors. The screening question was: 'Does the patient have a mental health problem(s) that currently affects their ability to deal with money?' (yes/no/ don't know). If a health professional answers 'yes' to this question, they are instructed to continue and complete the DMHEF. Alternatively, if the professional answers 'no', they are instructed not to provide any further information about the individual. In this case, once any arrangements for the service user to add a personal statement to the DMHEF are fulfilled, the professional is instructed to simply sign and return the form.

Second, the DMHEF now more explicitly instructs health professionals only to provide information relevant to individuals' money management abilities.

Third, the DMHEF now recommends that patients be allowed to review and provide written comments on the completed form before it is sent to creditors/money advisors, highlighting any perceived inaccuracies and reflecting UK law governing other forms of medical report.

\section{Revisions of questions on diagnosis and prognosis}

Considerable attention was given to the DMHEF questions concerning either diagnostic information or the provision of a prognosis. The former was perceived by some respondents as potentially stigmatising and open to misunderstanding among creditor/money advice professionals. However, this question was retained. On balance, the study team felt that a diagnosis legitimised the sick role, conferred advantages to the individual with debt who was requesting a flexible and sympathetic approach from creditors, and was also a central element of other forms such as the Driving Vehicle Licensing Authority, ${ }^{7}$ the Court of Protection ${ }^{8}$ and claims for Disability Living Allowance and Incapacity Benefit. ${ }^{9}$

The DMHEF question about prognosis led to substantial revisions. The study team recognised clinician and service user concerns about the provision of a prognosis. Subsequently, as part of written guidance for creditors and money advisors which accompanies the DMHEF, a new section was written explaining the difficulties of accurate and meaningful prognosis, detailing why health professionals cannot be expected to provide such prognoses in the DMHEF, and warning against creditors or money advisors attempting this themselves. The DMHEF item about prognosis was replaced by questions which provide further background information, including the first onset, most recent onset, and current status of an individual's mental disorder. Finally, the question order of the DMHEF was changed to reflect a more logical sequence.

\section{Other developments to support the DMHEF}

To ensure the revised DMHEF minimised the risk of personal information being unnecessarily shared across the health and commercial sectors, it was submitted to the Information Commissioner's Office who approved it as complying with UK data protection law on processing sensitive information. This approval statement was included in an accompanying manual of guidelines for creditors/ money advisors on using the DMHEF. Interestingly, no participants specifically raised issues about the Data Protection Act in their responses.

Finally, a website aiming to improve creditor/money advisor knowledge on mental health was developed in partnership with the Money Advice Liaison Group (www. moneyadvicetrust.org/section.asp?sid=12). This, however, is a small contribution towards a potentially much larger problem.

\section{Methodological considerations}

The DMHEF evaluation was limited by a small and nonrandom sample. Second, methods of questionnaire distribution did not allow response rate calculations, and a 'second wave' of evaluation data were not collected following the revision of the DMHEF to allow changes in clarity or relevance scores to be established. Third, the evaluation study focused on the wording and format of the DMHEF questions, rather than the use of the DMHEF with real-life clients in actual health, creditor, and advisor settings. Consideration was given to whether a similar study could be conducted in which health professionals were asked to evaluate the DMHEF based on their completion of such a form in a real-life scenario, and whether creditors/money advisors could evaluate the form based on these real-life data. However, resource and time constraints precluded such a study proceeding in a manner which was both ethical and practical. Instead, the study focused on the first stage in the development of any standardised form: question content and instrument format. Fourth, it is possible that an analytically useful distinction could have been made during sampling and data collection between medical and non-medical staff (particularly in regard to the ease or feasibility of reporting clinical data using the DMHEF), and staff with or without experience of working with patients experiencing debt and mental health problems. Finally, although not a study limitation, some creditors or money advisors might choose to ignore warnings and use information from the DMHEF to formulate their own 'lay prognoses' about when a client might be able to repay a debt. This misuse of the DMHEF violates published guidelines signed-up to by membership bodies in the creditor and money advice sectors ${ }^{4}$ and should therefore be monitored, challenged and regulated by these membership organisations.

\section{Conclusion}

The DMHEF provides a tool which shows potential for standardising communication between health professionals, creditors, money advisors, and people reporting mental health and debt problems. Although the sharing of personal data between the health and commercial sector presents 
risks, the DMHEF aims to minimise the amount of data that is shared (saving health professionals time and encouraging completion), without compromising any potential benefit to creditors, money advisors, or the individual with debt and mental health problems. A mixed-methods evaluation has now been funded in real-life creditor, advice and health settings to: ascertain whether the DMHEF informs effective decision-making; describe any barriers to its use and correct implementation; and identify what mental health education creditor and money advice organisations need.

\section{Funding}

The study was funded by the Money Advice Trust's research grant programme. C.F. has received research and educational materials grants from the following organisations: the Money Advice Trust, Finance and Leasing Association, Friends Provident Foundation, and Financial Services Authority. S.T. has worked on a research grant provided by the Money Advice Trust.

\section{About the authors}

Chris Fitch, Research Fellow, and Robert Chaplin, Research Fellow, work at the Royal College of Psychiatrists' Research Unit, London. Simon Tulloch
Research and Service Development Officer, Academic Unit, works at the Newham Centre for Mental Health, East London NHS Foundation Trust.

\section{References}

1 Office for National Statistics. The Social and Economic Circumstances of Adults with Mental Disorders. TSO (The Stationery Office), 2002.

2 Department of Trade and Industry. Tackling Over-Indebtedness. Department of Trade and Industry, 2006

3 Mind. In the Red: Debt and Mental Health. Mind, 2007

4 Money Advice Liaison Group. Good Practice Guidelines: Debt Management and Debt Collection in Relation to People with Mental Health Problems. MALG, 2007.

5 Edwards S. In Too Deep: CAB Clients' Experiences of Debt. Citizens Advice Bureau, 2003.

6 Royal College of Psychiatrists. Debt and mental health - resources for health and social care workers. Royal College of Psychiatrsits, 2010 (http://www.rcpsych.ac.uk/debt).

7 Harris M. Psychiatric conditions with relevance to fitness to drive. Adv Psychiatr Treat 2000; 6: 261-9.

8 MacFarlane AB. Medical evidence in the Court of Protection. Psychiatr Bull 1985; 9: 26-8.

9 Killoughery M. Disability and incapacity benefits. The role that doctors play. Psychiatr Bull 1999; 23: 260-3.

\title{
Recreational drugs and health information provided in head shops
}

\author{
Divina Pillay, ${ }^{1}$ Brendan D. Kelly ${ }^{1}$
}

The Psychiatrist (2010), 34, 100-102, doi: 10.1192/pb.bp.108.024646

${ }^{1}$ University College Dublin, Ireland Correspondence to Brendan D. Kelly (brendankelly35@gmail.com)
Aims and method To determine which recreational drugs are most readily offered in 'head shops', and what safety information is provided; and determine sales assistants' knowledge about the mental health complications of cannabis. Researchers surveyed ten head shops in Dublin.

Results Sales assistants in all head shops described their products as legal and safe. Overall, 50\% stated cannabis was generally not harmful, although 50\% stated it might cause depression and $60 \%$ stated it might cause psychosis in susceptible people. Salvia was available in $90 \%$ of outlets, although sales assistants in $78 \%$ warned about its potency.

Clinical implications Legal, psychoactive drugs, some of which are banned in other jurisdictions, are readily available in Dublin head shops. Enhanced awareness and effective regulation are required.

Declaration of interest None.
'Head shops' are retail outlets that sell legal recreational drugs, herbal mixtures which can be smoked, and various paraphernalia which can be used for the growth and consumption of cannabis. Head shops do not sell cannabis, which is illegal in the Republic of Ireland, the UK and many other jurisdictions.

Head shops first came to prominence in the USA in the 1960s, with the opening of the Psychedelic Shop on Height 